\title{
Mapping change in medical student attitudes regarding lesbian, gay and bisexual healthcare
}

\author{
Kaitlyn C. McCune, BA, ${ }^{1}$ Katherine L. Imborek, MD, ${ }^{2}$ Theang Ho, MS, ${ }^{1}$ Abbey J. Hardy- \\ Fairbanks, MD, ${ }^{3}$ Colleen K. Stockdale, MD, $\mathrm{MS}^{3}$
}

Keywords: Medical student, attitudes, medical student attitudes, lesbian, gay, bisexual, transgender, healthcare

\begin{abstract}
Despite significant social advances among lesbian, gay, bisexual, and transgender (LGBT) individuals, healthcare disparities remain prevalent. Medical education represents a prime opportunity for addressing this need. Thus, we undertook this study to explore second year medical students' attitudes regarding equal access to healthcare services including erectile dysfunction medication, family planning medications and technology, and partner health insurance coverage.
\end{abstract}

Nearly 1500 allopathic medical students were surveyed from 2006 to 2014 during their second pre-clinical training year. While attitudes regarding care between $L G B$ patients and heterosexual patients were often similar, there was a significant change in favor of providing insurance coverage for in-vitro and assisted reproduction services for lesbian women (increasing from $70 \%$ of students in favor in 2008 to $87 \%$ of students in 2013). Similarly, the proportion of students in favor of providing health insurance coverage for prescription drugs to same sex partners significantly increased from 2009 to 2013. Additionally, students noted healthcare providers should be required to provide equal access to care for all patients regardless of marital status or sexual practices (96\% agreement in 2006 and 98.6\% agreement in 2014).

Even with this significant increase in medical student approval of certain healthcare services for $L G B$ patients, continuing to integrate $L G B T$ healthcare topics into medical education curriculum remains critically important.

${ }^{1}$ University of lowa Carver College of Medicine, lowa City, lowa

${ }^{2}$ University of lowa Hospitals and Clinics, Department of Family Medicine, lowa City, lowa

${ }^{3}$ University of lowa Hospitals and Clinics, Department of Obstetrics and Gynecology, lowa City, lowa

\section{Introduction}

While significant social advances have been made over the last 10 years on the front of lesbian, gay, bisexual, and transgender (LGBT) rights and visibility, healthcare disparities in this population are still present. Buchmueller and Carpenter reported in 2010 that women in same-sex partnerships were not only more likely to report unmet healthcare

Please cite this paper as: McCune KC, Imborek KL, Ho T, Hardy-Fairbanks AJ, Stockdale CK. Mapping change in medical student attitudes regarding lesbian, gay and bisexual healthcare. Proceedings in Obstetrics and Gynecology, 2015;5(2):Article 2 [ 9 p.]. Available from: http://ir.uiowa.edu/pog/ Free full text article.

Corresponding author: Kaitlyn C. McCune, University of lowa Carver College of Medicine, lowa City, lowa, kaitlynmccune@uiowa.edu

Financial Disclosure: The authors report no conflict of interest.

Copyright: (c) 2015 McCune et al. This is an open-access article distributed under the terms of the Creative Commons Attribution License, which permits unrestricted use, distribution, and reproduction in any medium, provided the original author and source are credited. 
needs, but were also less likely to have health insurance, to have had a check up in the last year, and to have had a recent mammogram or Pap test. ${ }^{1}$ Similarly, they identified that men in same-sex relationships were less likely than their peers in opposite-sex relationships to have health insurance and more likely to have unmet healthcare needs. The CDC reported in its National Health Statistics Report for 2014 that women who identified as gay, lesbian, or bisexual were less likely than their straight peers to have a regular place to receive healthcare. ${ }^{2}$ Furthermore, adults who identified as bisexual were less likely than those who identified as straight to obtain needed medical care due to cost. ${ }^{2}$

Medical education represents a prime opportunity for addressing these disparities. Indeed, there has been increased research regarding the need for integrating LGBT health issues into medical curriculum. Burke et al. examined bias in a sample of selfidentified heterosexual medical students. Nearly half of the medical students had some degree of explicit bias toward gay and lesbian persons, as defined by self-reported measures of conscious attitudes. Additionally, 81.5\% of medical students had implicit bias against gay and lesbian individuals, determined using validated measures of unconscious responses. ${ }^{3}$ In a study conducted with osteopathic medical students, Lapinski et al. found that while study participants had favorable levels of acceptance towards LGBT patients, the medical knowledge of this population was significantly lower among self-identified heterosexual students compared to self-identified lesbian, gay, and bisexual (LGB) students. $^{4}$ In a study of medical students, residents and fellows, it was reported that participants were significantly less comfortable taking sexual histories and addressing sexual health concerns in self-identified LGBT and queer patients. ${ }^{5}$

In addition to studies regarding the need for LGBT-inclusive curricula, several studies have illustrated the impact of personal interaction on medical student attitudes. Burke et al. identified that both increased amount of contact with gay and lesbian individuals and favorability of that contact were associated with more positive implicit and explicit attitudes toward LGBT patients. ${ }^{3}$ This finding was previously found in 2006 in a study of third and fourth year medical students in New York which noted that greater clinical contact with LGBT patients was associated with more comprehensive history taking for all patients, greater knowledge of LGBT healthcare issues and more positive attitudes towards LGBT patients. ${ }^{6}$

However, no current study investigates whether there has been a change in medical student attitudes regarding equal access to specific healthcare services for LGBT patients over time. This study seeks to compare the approval rates of individual classes of second year medical students from 2006 to 2014 regarding equal access to healthcare services including erectile dysfunction medication, family planning medications and technology, and partner health insurance coverage. 


\section{Methods}

An anonymous twenty-seven-item survey was given to all medical students in the fall of their second year at a Midwestern allopathic medical school from 2006 through 2014. Between 145 and 183 students participated in the study each year for a total of 1,499 students over the course of nine years. Questions were asked about erectile dysfunction (ED), society, family and homosexuality. Twenty-four questions had yes or no answers; three questions had multiple-choice answers. Survey data was then pooled and assessed by year.

\section{Results}

\section{Erectile Dysfunction}

When compiling all answers across years, $98 \%(\mathrm{SD}=0.02, \mathrm{n}=9, \mathrm{Cl} 95=$ $(0.97,1.0))$ of students stated that they would prescribe erectile dysfunction (ED) medication to a heterosexual man who would like to have sexual intercourse with his wife. In the same time span, 95\% (SD $=0.010, \mathrm{n}=9$, $\mathrm{Cl} 95=(0.95,0.96))$ of all participants endorsed giving medication to a gay man desiring to have anal intercourse with his male partner. Figure 1 illustrates the trend in this data from 2006 and 2014. In 2010 and 2014 there were significantly more $(p<0.05)$ students who would provide ED medication to heterosexual men versus the number who would provide ED medication to gay men. Additionally, when all students over all years were combined, significantly more students would provide ED medications to heterosexual men than would provide ED medications to gay men. However, for neither group was there was a statistically significant change in medical student attitudes over time.

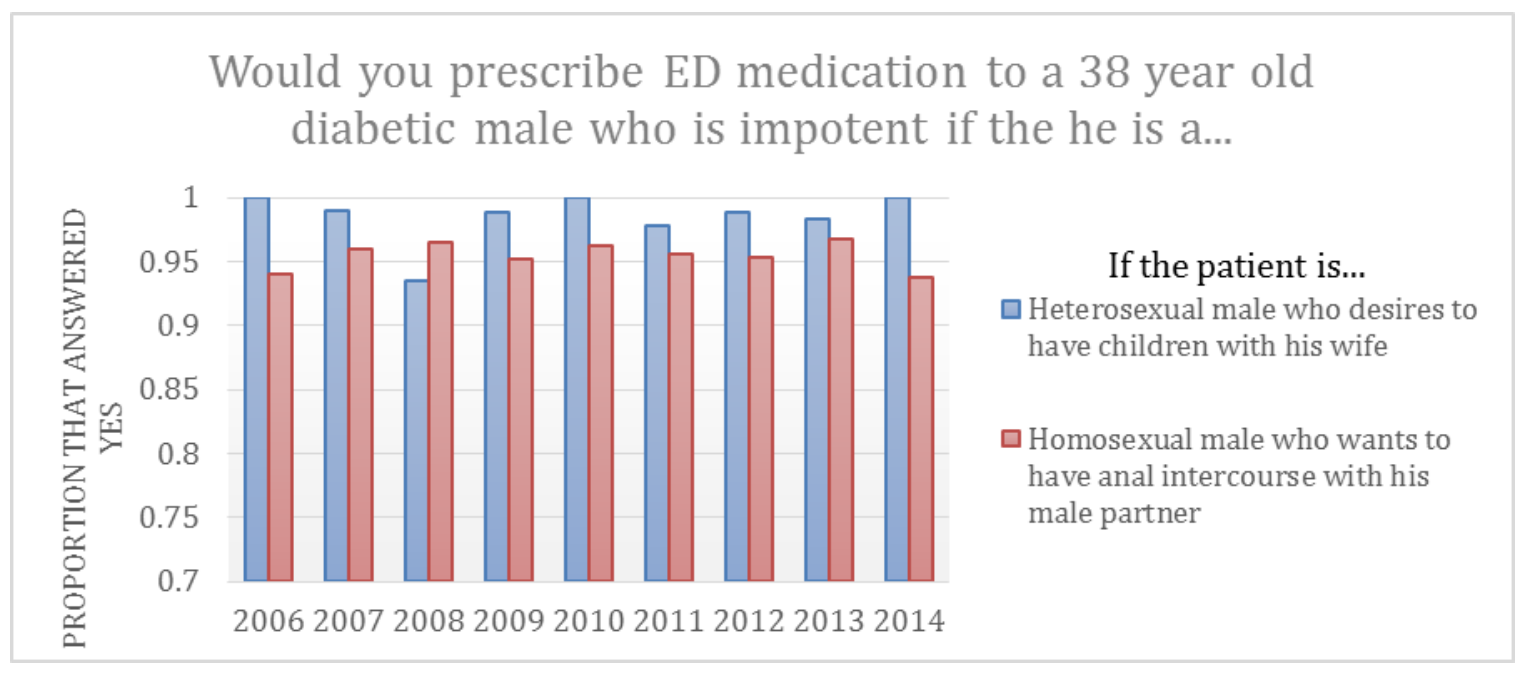

Figure 1. Prescribing Erectile Dysfunction Medication 
Society, Family and Homosexuality

Within each year, there was no significant difference between the percentage of students who believed that insurance coverage of oral contraceptives should be provided for heterosexual women as compared to bisexual women. The same is true when students were asked about insurance coverage of erectile dysfunction medications for heterosexual versus gay men.

However, when asked about insurance coverage for in-vitro and assisted reproduction services for heterosexual and lesbian women, significant differences and changes were noted. From 2008 to 2014, there was a significant increase between years in favor of providing coverage for lesbian women. Seventy percent of students were in favor in 2008, increasing to $87 \%$ in favor in 2013. Between 2013 and 2014 , there was a decrease, though not statistically significant, to $83 \%$ of students in favor of providing coverage of these services to lesbian women. A similar trend was seen with heterosexual women between 2013 and 2014. When comparing students' attitudes within years, support for providing coverage to heterosexual as compared to lesbian women was significantly higher $(p<0.05)$ in 2008 and 2011. However, from 2011 to 2013, the difference between the percentage of students in favor of providing coverage to heterosexual women and the percentage of students in favor of providing coverage to lesbian women has decreased significantly $(p<<0.01)$. Figure 2 illustrates these values.

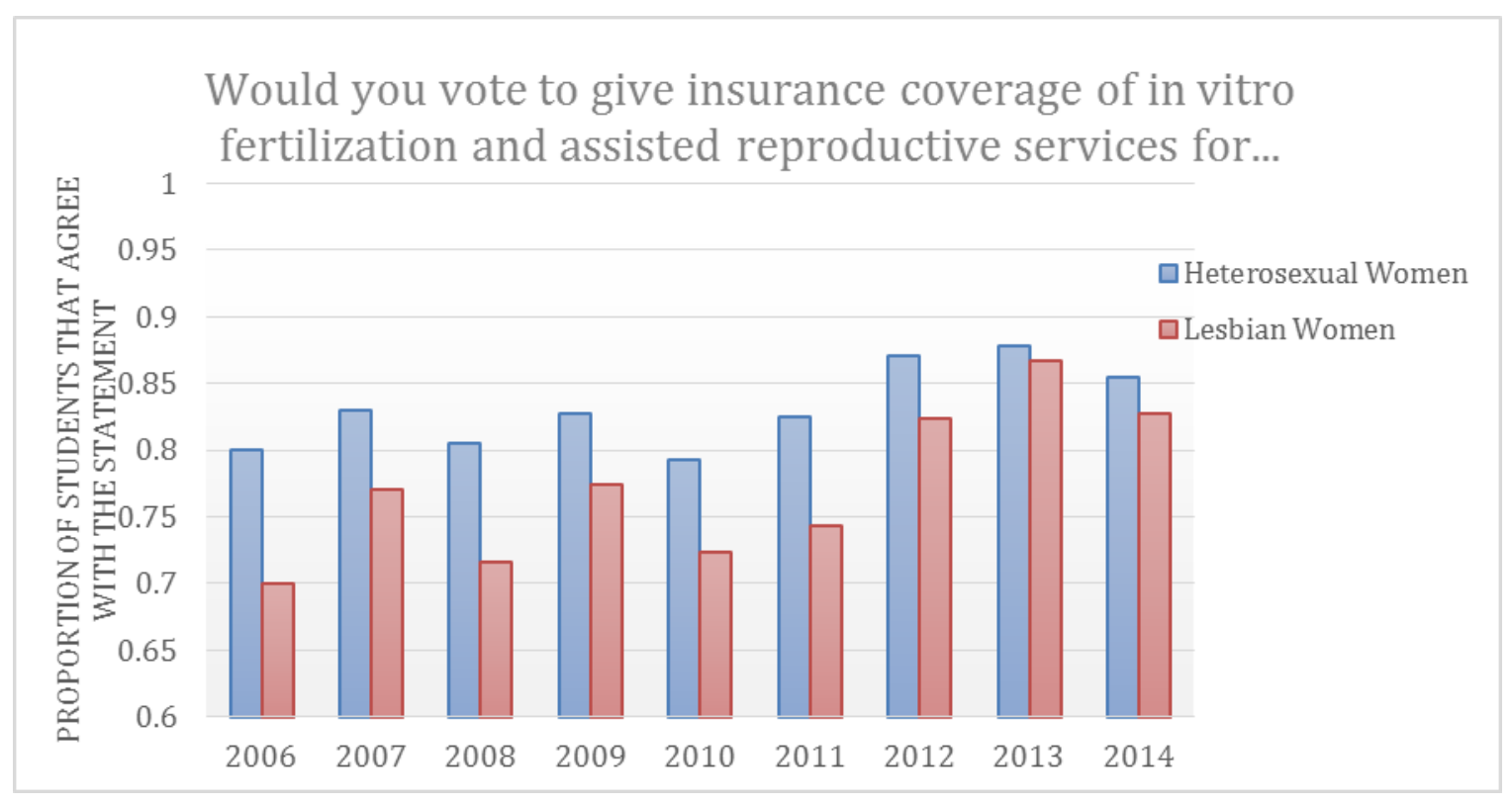

Figure 2. Attitudes regarding insurance coverage for in-vitro and assisted reproduction services 
Figure 3 illustrates student attitudes regarding prescription drug coverage for opposite sex versus same sex spouses/partners. Significantly $(p<0.003)$ fewer students within each class were in favor of providing coverage to the same sex partner in the years 2008-2012. However, in 2013 and 2014 there was no statistical difference in the percentage of students in favor of providing prescription drug coverage to the heterosexual spouses and the percentage of students in favor of providing drug coverage to the same sex partners. Of note, there is a significant increase $(p=0.0011)$ in the proportion of students in favor of providing drug coverage for same sex couples from 2009 to 2013.

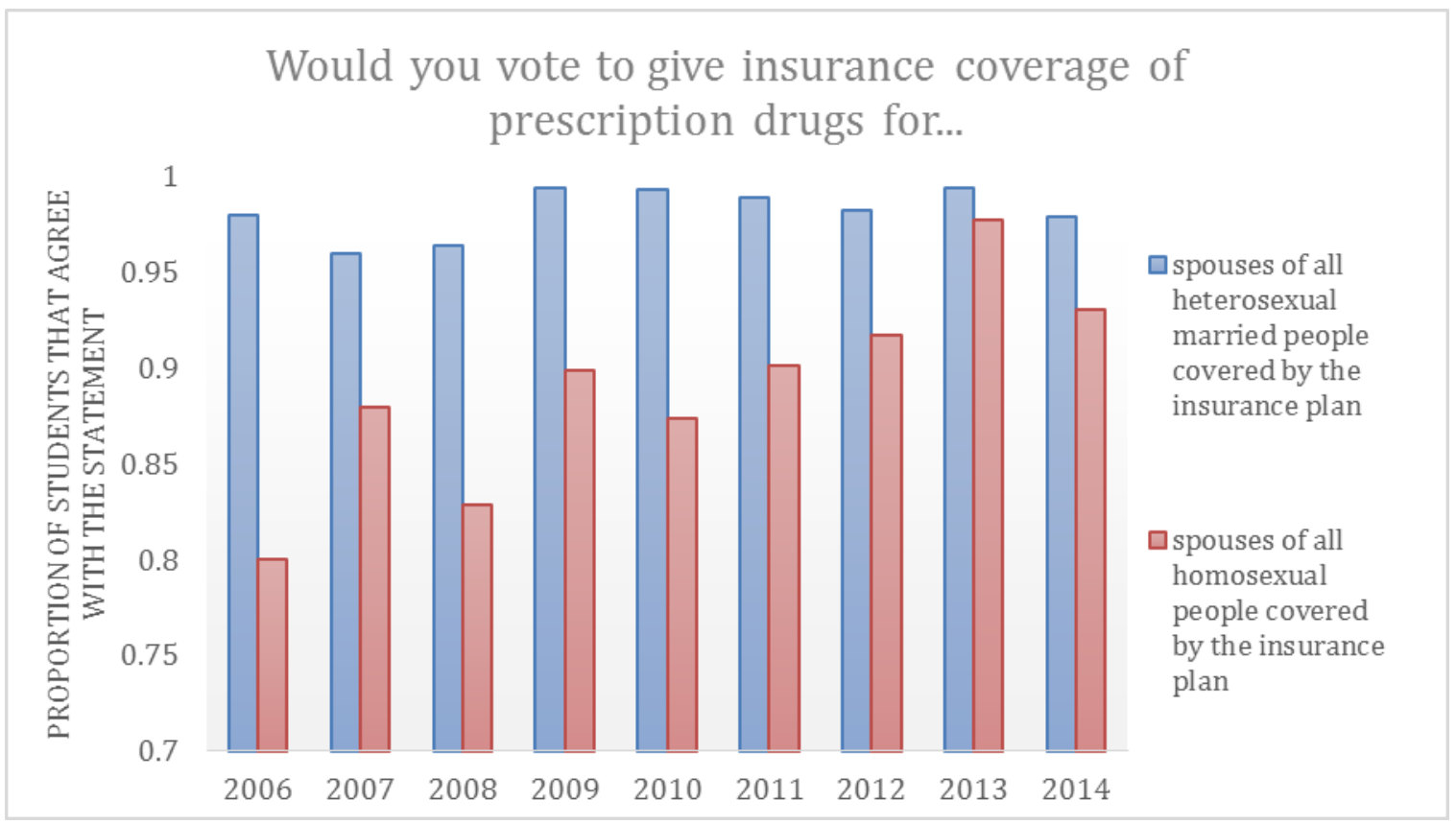

Figure 3. Attitudes regarding prescription drug coverage

When asked whether students believed that healthcare providers in public healthcare facilities should be required to provide equal access to care for all patients regardless of marital status or sexual practices, there was an overall positive trend from 2006 until 2014. However, there was no significant difference between $96 \%$ of student agreeing in 2006 and $98.6 \%$ of students agreeing in 2014. Figure 4 illustrates these values. 


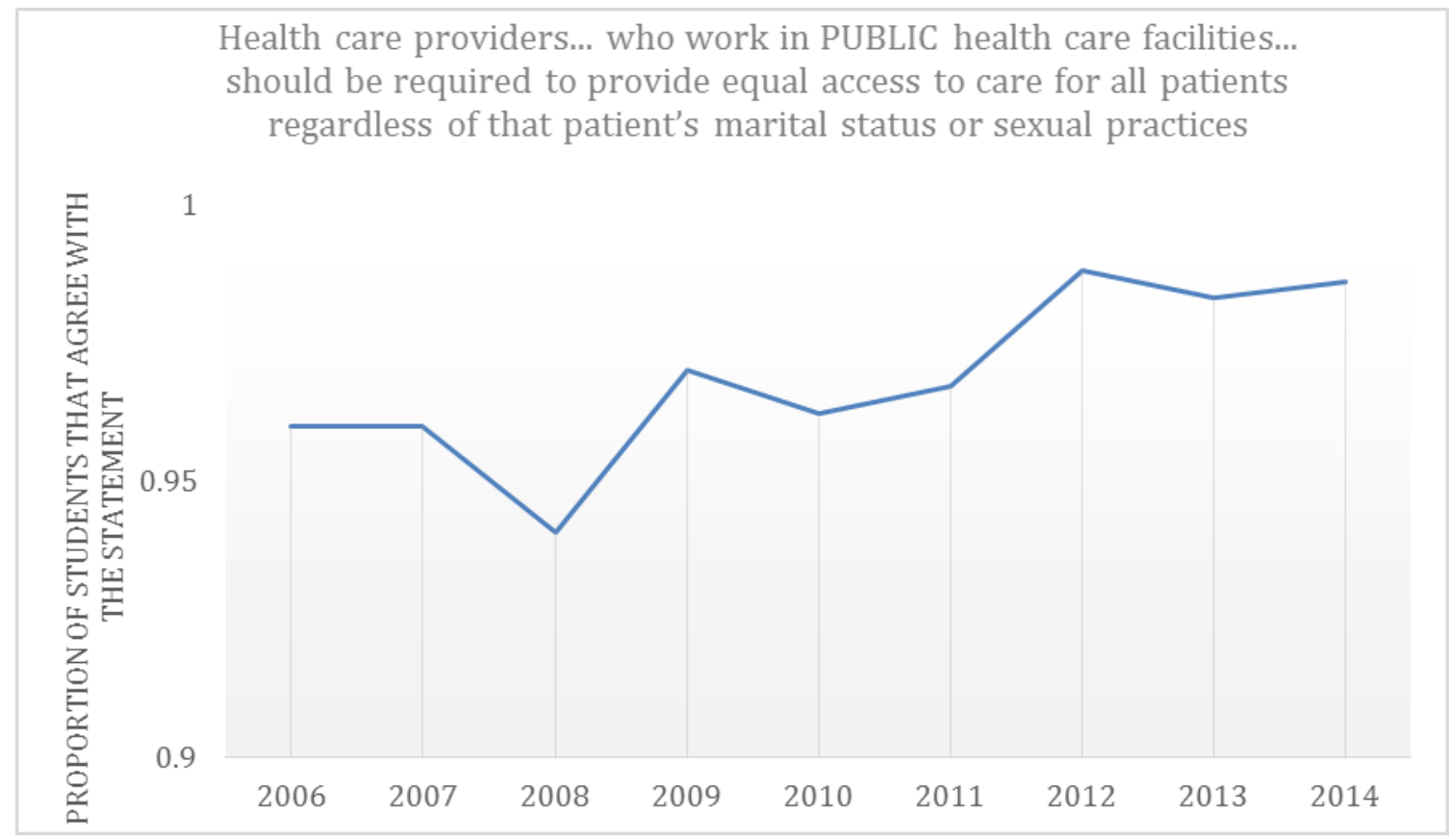

Figure 4. Attitudes regarding provision of care by health care providers in public health care facilities.

\section{Discussion}

From 2006 to 2014, there has been a significant shift in medical student attitudes regarding equal access to healthcare services including reproductive technologies and partner insurance coverage for LGBT patients. This is best illustrated in trends for assisted reproductive technology for lesbian women and prescription drug insurance coverage for same-sex partners (see Figures 2 and 3). These changes could reflect a multitude of factors. First, there have been substantial societal moves towards greater acceptance of those who identify as LGBT. Marriage equality came to lowa in 2009 and to 37 states by 2014. Attitudes regarding partner insurance benefits for same-sex couples showed a statistically significant $\quad(p<0.001)$ increase of $18 \%$ in acceptance between
2006 and 2013, paralleling the sentiments of lowans regarding approval of same-sex marriage. According to an lowa poll in 2014, 34\% of lowans were disappointed with marriage equality in lowa, a decrease from 62\% who opposed marriage equality in 2008. ${ }^{7}$ Furthermore, the medical school increased LGBT-specific required and selective curriculum over those years, with 2014 including an entire week of sexuality-based healthcare education for second year medical students. From 2006 through 2008, LGBT health issues were mentioned in four pre-clinical medical student lectures including one dedicated LGBT health lecture. Over the course of 2009 through 2014, there was a progression of curricular integration of LGBT health issues from the incorporation of LGBT patients into multiple lectures, case scenarios and 
simulated patients, to having dedicated lectures covering care of LGB patients and transgender patients in addition to child/adolescent sexuality and gender identity.

Despite this increase in medical student approval of equal access to certain healthcare services for LGB patients, continuing to integrate LGBT curriculum throughout the preclinical and clinical years remains critically important. This study does not assess student comfort in addressing LGBT-specific healthcare issues. Though as mentioned, previous studies have shown decreased level of comfort in medical student, residents, and fellows in addressing LGBT healthcare concerns. ${ }^{4,5}$ Curriculum changes are an integral aspect of continuing to chart a positive change in attitudes as studies have shown the association between greater exposure to LGBT patients and LGBT health curriculum with more positive attitudes regarding caring for these patients. ${ }^{3,6}$

Two recent studies have confirmed that sexual minority medical students have increased emotional stress as compared to their heterosexual peers. Przedworski et al. in 2015 found that sexual minority medical students were significantly more likely to report depressive and anxiety symptoms, harassment, isolation, and social stressors when compared to their heterosexual peers. ${ }^{8}$ Lapinski and Sexton had similar findings in 2014 among a nationwide sample of osteopathic medical students. In their study, LGB medical students had higher levels of depression, lower levels of perceived social support and greater levels of discomfort with disclosure of sexual orientation when compared to their heterosexual peers. Notably, this study also found that a majority of medical students surveyed rated their campus as noninclusive. ${ }^{9}$ While no study has directly evaluated possible interventions to improve the campus climate for sexual minority medical students, curricular changes may be integral to supporting LGBT identified medical students and providing a more welcoming and inclusive educational environment.

Expanded LGBT healthcare curriculum increases the level of knowledge and comfort in addressing LGBT healthcare concerns. Saqueira et al found educational sessions focusing on LGBT healthcare were valued and meaningful to preclinical medical students. Following each of the four educational sessions, the investigators found that participants acknowledged the previous lack of exposure to LGBT content, found the information provided applicable, and felt that the content should be integrated into the required medical school curriculum. ${ }^{10}$

Limitations of our study include a lack of inclusion of the demographic and religious characteristics of each class surveyed and survey questions that only focused on approval of equal access to healthcare services. Enhanced demographic data could provide insight into potential associations between medical student attitudes regarding LGBT healthcare and gender, sexual identity, age, geographical region and religious affiliation. Obtaining validated measures of medical student bias and overall attitudes towards LGBT patients would identify potential needs for increased positive exposure to LGBT persons. Asking additional questions that would assess level of knowledge of 
LGBT healthcare issues and comfort in working with LGBT patients would allow specific targeting for future curricular changes to areas with knowledge deficits. Further, studies including more metropolitan schools outside of the Midwest would allow for a nationwide understanding of attitudes regarding provisions of healthcare for LGBT patients.

There has been a significant increase in favorable attitudes of second year medical students regarding the provision of assisted reproductive technology for lesbian women and insurance coverage for same sex partners. Specific factors impacting students' attitudes were not queried. However, it is likely that the changes are a reflection of multiple curricular and societal factors.

\section{References}

1. Moran C, Arriaga M, Rodriguez G, Moran S. Obesity differentially affects phenotypes of polycystic ovary syndrome. Int J Endocrinol. 2012;2012:317241. doi: 10.1155/2012/317241. Epub 2012 Jul 8. PubMed PM Ward BW, Dahlhamer JM, Galinsky AM, Joestl SS.

2. Sexual orientation and health among U.S. adults: national health interview survey, 2013. Natl Health Stat Report. 2014 Jul 15;(77):1-10. PubMed PMID: 25025690.ID: 22829818.

3. Burke SE, Dovidio JF, Przedworski JM, Hardeman RR, Perry SP, Phelan SM, Nelson DB, Burgess DJ, Yeazel MW, van Ryn M. Do Contact and Empathy Mitigate Bias Against Gay and Lesbian People Among Heterosexual First-Year Medical Students? A Report From the Medical Student CHANGE Study. Acad Med. 2015 May;90(5):645-51. doi: 10.1097/ACM.0000000000000661. PubMed PMID: 25674910.
4. Lapinski J, Sexton P, Baker L. Acceptance of lesbian, gay, bisexual, and transgender patients, attitudes about their treatment, and related medical knowledge among osteopathic medical students. J Am Osteopath Assoc. 2014 Oct;114(10):788-96. doi: 10.7556/jaoa.2014.153. PubMed PMID: 25288714.

5. Hayes V, Blondeau W, Bing-You RG. Assessment of Medical Student and Resident/Fellow Knowledge, Comfort, and Training With Sexual History Taking in LGBTQ Patients. Fam Med. 2015 May;47(5):383-7. Pub Sanchez NF, Rabatin J, Sanchez JP, Hubbard S, Kalet A.

6. Medical students' ability to care for lesbian, gay, bisexual, and transgendered patients. Fam Med. 2006 Jan;38(1):21-7. PubMed PMID: 16378255.Med PMID: 25905882.

7. Jackson S. lowa Poll: Top gay marriage response: A shrug. The Des Moines Register. Mar 6, 2014. http://archive.desmoinesregister.com/art icle/20140307/NEWS/303070095/lowa$\mathrm{P}$

8. Przedworski JM, Dovidio JF, Hardeman RR, Phelan SM, Burke SE, Ruben MA, Perry SP, Burgess DJ, Nelson DB, Yeazel MW, Knudsen JM, van Ryn M. A Comparison of the Mental Health and Well-Being of Sexual Minority and Heterosexual First-Year.Medical Students: A Report From the Medical Student CHANGE Study. Acad Med. 2015 May;90(5):652-9. doi: 10.1097/ACM.0000000000000658.

PubMed PMID: 25674912.

9. Lapinski J, Sexton P. Still in the closet: the invisible minority in medical education. BMC Med Educ. 2014 Aug 15;14:171. doi: 10.1186/1472-6920-14171. PubMed PMID: 25128252. 
10. Sequeira GM, Chakraborti C, Panunti BA. Integrating Lesbian, Gay, Bisexual, and Transgender (LGBT) Content Into Undergraduate Medical School Curricula: A Qualitative Study. Ochsner J. 2012 Winter;12(4):379-82. PubMed PMID: 23267268. 